\title{
Characterising the relationship between weather extremes in Europe and synoptic circulation features
}

\author{
S. Pfahl \\ Institute for Atmospheric and Climate Science, ETH Zurich, 8092 Zurich, Switzerland \\ Correspondence to: S. Pfahl (stephan.pfahl@env.ethz.ch) \\ Received: 22 January 2014 - Published in Nat. Hazards Earth Syst. Sci. Discuss.: 26 February 2014 \\ Revised: - Accepted: 30 April 2014 - Published: 6 June 2014
}

\begin{abstract}
Extreme weather events in Europe are closely linked to anomalies of the atmospheric circulation and in particular to circulation features like cyclones and atmospheric blocking. In this study, this linkage is systematically characterised with the help of conditional cyclone and blocking frequencies during precipitation, wind gust and temperature extremes at various locations in Europe. Such conditional frequency fields can serve as a dynamical fingerprint of the extreme events and yield insights into their most important physical driving mechanisms. Precipitation extremes over the ocean and over flat terrain are shown to be closely related to cyclones in the vicinity and the associated dynamical lifting. For extreme precipitation over complex terrain, cyclone anomalies are found at more remote locations, favouring the flow of moist air towards the topography. Wind gust extremes are associated with cyclone and blocking anomalies in opposite directions, with the cyclones occurring mostly over the North and Baltic seas for extreme events in central Europe. This setting is associated with pronounced surface pressure gradients and thus high near-surface wind velocities. Hot temperature extremes in northern and central Europe typically occur in the vicinity of a blocking anticyclone, where subsidence and radiative forcing are strong. Over southern Europe, blocking anomalies are shifted more to the north or northeast, indicating a more important role of warm air advection. Large-scale flow conditions for cold extremes are similar at many locations in Europe, with blocking anomalies over the North Atlantic and northern Europe and cyclone anomalies southeast of the cold extreme, both contributing to the advection of cold air masses. This characterisation of synoptic-scale forcing mechanisms can be helpful for better understanding and anticipating weather extremes and their long-term changes.
\end{abstract}

\section{Introduction}

Extreme events like the central European floods in 2002 (Ulbrich et al., 2003a) and 2013 (Grams et al., 2014), the heat waves in 2003 (Schär et al., 2004) and 2010 (Barriopedro et al., 2011) and winter storms "Lothar" in 1999 (Wernli et al., 2002) and "Klaus" in 2009 (Liberato et al., 2011) caused severe damages and various fatalities in Europe. A characterisation of the processes leading to such meteorological extreme events and a proper representation of these processes in climate models is central for assessing potential future changes in the occurrence of weather extremes (e.g. Beniston et al., 2007; Cattiaux et al., 2012). In the first place, extremes in near-surface temperature, wind speed and precipitation occur due to anomalies in the atmospheric circulation.

Numerous studies have investigated this linkage between circulation and weather extremes using statistical methods. In particular, the relationship between temperature extremes in Europe and large-scale circulation patterns has been widely studied (Yiou and Nogaj, 2004; Cassou et al., 2005; Santos and Corte-Real, 2006; Della-Marta et al., 2007; Jacobeit et al., 2009; Rodriguez-Puebla et al., 2010; Andrade et al., 2012). These studies highlighted the important role of the North Atlantic Oscillation (NAO) for temperature extremes in winter. In addition, atmospheric blocking in the eastern North Atlantic region has been shown to lead to extremely cold winter conditions in Europe (Sillmann and Croci-Maspoli, 2009; Sillmann et al., 2011; Buehler et al., 2011). Both an increased blocking activity and a negative phase of the NAO (which are intrinsically related, cf. CrociMaspoli et al., 2007b) are associated with a weakening of the westerly flow and enhanced import of cold Arctic air masses into Europe. Following this reasoning, the relatively cold 
winter conditions in Europe during recent years have been attributed to an increased frequency of anticyclonic circulation patterns (Cattiaux et al., 2010; Zhang et al., 2012). During summer hot temperature extremes are associated with anticyclonic circulation anomalies (Cassou et al., 2005; Carril et al., 2008; Stefanon et al., 2012; Pfahl and Wernli, 2012c). In this case (and particularly for more northerly parts of Europe), not horizontal temperature advection, but adiabatic warming in sinking air masses and an anomalous clear-sky radiative forcing during anticyclonic conditions are thought to be the most important mechanism (Pfahl and Wernli, 2012c; Bieli et al., 2014). In addition, summer heat extremes can be amplified through soil moisture feedbacks (e.g. Fischer et al., 2007; Vautard et al., 2007; Zampieri et al., 2009; Seneviratne et al., 2010; Quesada et al., 2012).

Also for wind speed and precipitation extremes in Europe, many studies investigated the statistical relationship of the extremes to large-scale circulation patterns and weather types (see Leckebusch and Ulbrich, 2004; Leckebusch et al., 2008; Nissen et al., 2010; Donat et al., 2011 for wind storms; Yiou and Nogaj, 2004; Scaife et al., 2008; Jacobeit et al., 2009; Kenyon and Hegerl, 2010; Toreti et al., 2010 for precipitation extremes). For these two types of extreme events mid-latitude cyclones have been shown to be particularly important. While wind storms in northern and central Europe are mostly associated with cyclones over the North Atlantic and the North Sea (Donat et al., 2011; Hanley and Caballero, 2012), Mediterranean cyclones can cause wind extremes over southern Europe (Nissen et al., 2010). As for temperature extremes, large-scale circulation patterns like the NAO can influence the occurrence of wind storms through their correlation with cyclone frequencies. In several European regions, precipitation extremes are related to cyclones locally, i.e. extreme precipitation occurs close to the centre of a cyclone (Pfahl and Wernli, 2012a), indicating the importance of synoptic-scale lifting associated with cyclone intensification. This direct linkage is specifically relevant in the Mediterranean (see also Jansa et al., 2001; Reale and Lionello, 2013). Due to the small-scale character of precipitation, the occurrence of precipitation extremes can also be influenced by local-scale forcing mechanisms, e.g. related to orography. Previous studies have thus looked at such events in relatively confined regions, like for instance the UK (Maraun et al., 2011), the southern side of the Alps (Martius et al., 2006), or northwestern Italy (Pinto et al., 2013).

Many of the studies cited above investigated the circulation anomalies associated with extreme weather events on relatively long (seasonal or longer) temporal and large spatial scales, applying rather sophisticated statistical methods (e.g. cluster analysis or principal components) to characterise the complex spatio-temporal relationship between circulation and extremes. In this study, event-based linkages between extreme events and individual circulation features, namely cyclones and atmospheric blockings, are identified and characterised with the help of a relatively simple conditional frequency analysis. Extreme events and the associated mechanisms on short, sub-daily to daily timescales are studied, providing complementary information compared to previous investigations focusing on longer temporal scales. A major advantage of such a feature-based diagnostic is that the physical mechanisms associated with specific circulation features are well understood and therefore their linkage to weather extremes provides direct and intuitive insight into the atmospheric processes causing the extreme events. Furthermore, a relatively clear, physically based definition of the flow features allows the application of the same diagnostic also to model simulations of different climates (e.g. Ulbrich et al., 2010; Masato et al., 2013), avoiding, e.g., problems with the non-stationarity of specific weather types or circulation indices. Recently Pfahl and Wernli (2012a, c) quantified the local linkage of precipitation extremes to cyclones as well as of temperature extremes to blocking. In their analysis, the extreme event and the circulation feature had to be identified at the same location in order to establish a relationship between the two. Here, this approach is extended to also include remote effects of cyclones and blocking on weather extremes at different locations in Europe. Such remote effects are mainly linked to the anomalous wind field of the circulation feature, which also extends beyond the area directly associated with the cyclone or blocking. After introducing the basic data set and the methods in Sect. 2, results and discussions on different types of extreme weather events (precipitation, wind gust, hot and cold temperature extremes) are presented in Sects. 3.1-3.4. Conclusions follow in Sect. 4.

\section{Data and methods}

\subsection{Extreme events}

This study is based on data from the ERA-Interim reanalysis of the European Centre for Medium-Range Weather Forecasts (Dee et al., 2011) for the period 1989-2009. Since mean statistics of extreme events are investigated, this 21-year period is sufficient for obtaining robust results. All variables are interpolated to a $1^{\circ} \times 1^{\circ}$ geographical grid. For the definition of extreme weather events, six-hourly precipitation, $10 \mathrm{~m}$ wind gusts and $2 \mathrm{~m}$ maximum and minimum temperature from twice-daily short-term forecasts are applied, using forecast steps between 6 and 12 as well as 12 and $18 \mathrm{~h}$. A target region is defined covering large parts of central, western and southern Europe (red frame in Fig. 1b), and at each grid point within this target region, weather extremes are defined as the $1 \%$ most extreme six-hourly events with respect to the total 21 years climatology at the respective location. This corresponds to the selection of all six-hourly intervals above the 99th (or below the 1st) local percentile, yielding 306 events per grid point. More specifically, the following extreme events are considered: 


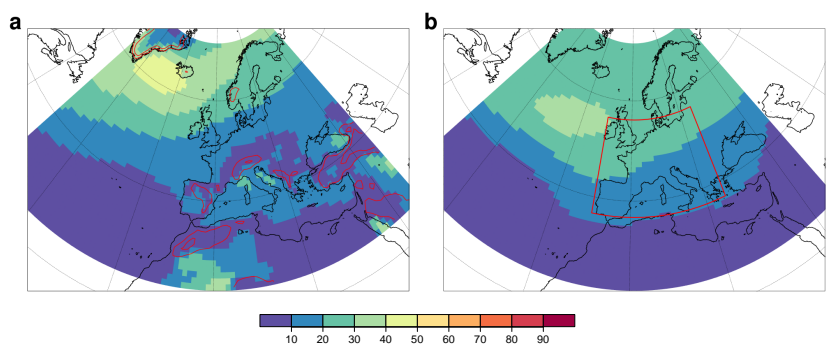

Figure 1. Annual mean (a) cyclone and (b) blocking frequency (in $\%$ ) for the period 1989-2009. Feature frequencies are shown in the analysis region covering Europe as well as parts of the North Atlantic, North Africa and the Middle East. Red contours in (a) indicate regions of high topography (shown are surface altitude contours of 800 and $1500 \mathrm{~m}$ according to the ERA-Interim topography). The red frame in (b) shows the target region where extreme weather events are studied.

- precipitation extremes: six-hourly accumulated precipitation above its 99th percentile,

- wind gust extremes: six-hourly maximum wind gust above its 99th percentile,

- hot temperature extremes: six-hourly maximum temperature above its 99 th percentile,

- cold temperature extremes: six-hourly minimum temperature below its 1 st percentile.

Note that due to the definition on a climatological basis (and not individually for each season), hot extremes usually occur in summer, whereas cold extremes are mostly found during the winter season. Since the extreme events are defined based on the ERA-Interim data set, they refer to spatial scales of roughly $10000 \mathrm{~km}^{2}$. Therefore, small-scale extremes, like convective precipitation and gusts caused by local thunderstorms, are not accounted for. Although the magnitude of the extreme events, in particular for precipitation and wind gusts, may be underestimated in ERA-Interim compared to point measurements, the timing and relative ranking of synopticscale extremes is thought to be properly represented in the reanalysis data. For instance, Pfahl and Wernli (2012a) found a good correspondence between the timing of precipitation extremes in ERA-Interim and in the CMORPH satellite data set (see Joyce et al., 2004). Della-Marta et al. (2009) analysed the representation of 200 severe European wind storms compiled from different observational sources in the ERA40 reanalysis, the predecessor of ERA-Interim. They found problems in the reanalysis wind gust data only in regions with high surface roughness, which were caused by a parameterisation issue that has been eliminated in ERA-Interim (cf. Dee et al., 2011). An advantage of using wind data from reanalysis is the improved temporal homogeneity compared to many measurement time series (Della-Marta et al., 2009; Pfahl et al., 2009).

\subsection{Identification of cyclones and blocking}

A slightly updated version of the algorithm of Wernli and Schwierz (2006) is applied for the automatic detection of cyclones from ERA-Interim sea level pressure (SLP) fields (cf. Pfahl and Wernli, 2012a). A cyclone is defined as an area bounded by a closed SLP contour and containing one or several SLP minima. SLP contours are detected at an interval of $0.5 \mathrm{hPa}$. Only systems with at least $1 \mathrm{hPa}$ difference between the SLP minimum and the outermost contour are taken into account. The maximum length of the outermost closed contour is limited to $7500 \mathrm{~km}$, and SLP minima at an altitude above $1500 \mathrm{~m}$ are not considered. Atmospheric blocking is also detected automatically using an algorithm developed by Schwierz et al. (2004) (see also Croci-Maspoli et al., 2007a; Pfahl and Wernli, 2012c). This algorithm is based on the vertically averaged potential vorticity (VAPV). Potential vorticity is calculated from three-dimensional ERAInterim temperature and horizontal wind fields and averaged between 500 and $150 \mathrm{hPa}$. Anomalies of VAPV are computed with respect to a monthly, grid-point based climatology and smoothed with a two-day running mean. Anticyclonic VAPV anomalies below a threshold of -0.7 potential vorticity units (pvu) are then identified and tracked in time. If these anomalies have a lifetime of more than 5 days (with a spatial overlap of at least $70 \%$ between consecutive six-hourly time steps), they are identified as blocking. Note that the threshold of $-0.7 \mathrm{pvu}$ is less restrictive than the original threshold of -1.3 pvu used by Schwierz et al. (2004) and Croci-Maspoli et al. (2007a), meaning that weaker blocking anomalies are also taken into account (as in Pfahl and Wernli, 2012c).

Both the identified cyclones and blocking anticyclones are two-dimensional structures, which, at each six-hourly time step, can be represented by Boolean fields (fields with value 1 in regions where cyclones or blockings are identified and 0 elsewhere). Averaging these Boolean fields over certain periods of time directly yields cyclone or blocking frequencies at each grid point. In this study, such frequencies are calculated within an analysis region covering Europe as well as parts of the North Atlantic, North Africa and the Middle East (Fig. 1). Both the climatological cyclone and blocking distributions have been discussed previously (Pfahl and Wernli, 2012a, c) and are consistent with results from earlier studies based on different data sets (e.g. Wernli and Schwierz, 2006; Croci-Maspoli et al., 2007a). Annual mean cyclone frequencies are largest in the main storm track region over the North Atlantic (Fig. 1a). Secondary maxima are found over the Mediterranean, which are mainly associated with a strong winter storm track in this region (Fig. 2a), and over North Africa and the Middle East. The latter maxima are partly due to the formation of heat lows during summer (Fig. 2b). The annual mean blocking distribution also has a maximum over the eastern North Atlantic (Fig. 1b). Blocking frequencies over central Europe and the Mediterranean are larger in winter than during summer (Fig. 2c and d). 


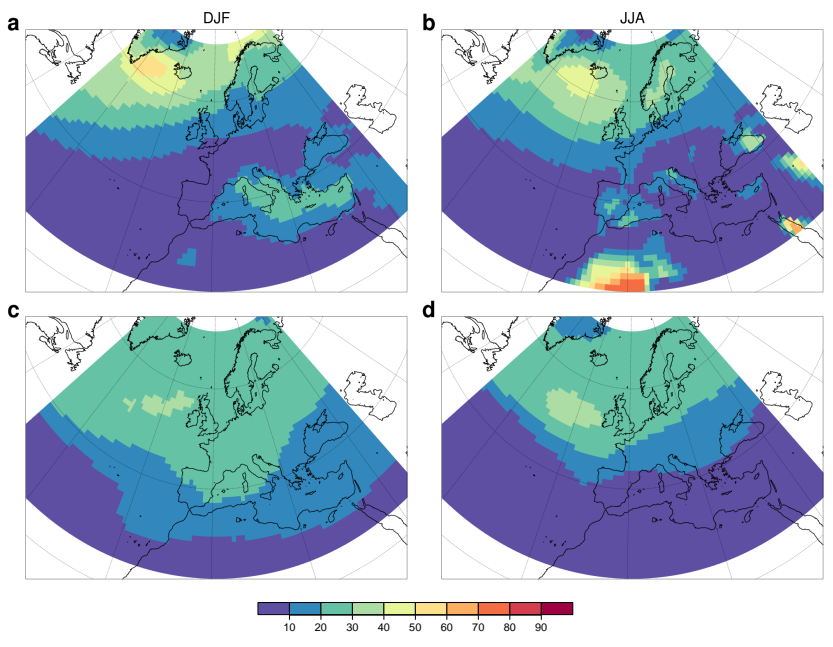

Figure 2. (a, b) Cyclone and (c, d) blocking frequencies (in \%) for (a, c) December to February (DJF, winter) and $(\mathbf{b}, \mathbf{d})$ June to August (JJA, summer) 1989-2009.

\subsection{Linkage between extreme events and circulation features}

To link weather extremes at a specific grid point to the occurrence of cyclones and blocking, conditional frequencies of the respective circulation feature are calculated by averaging the Boolean fields over periods with extreme events at the location under consideration (taking the time steps at the start and at the end of the six-hourly period into account). The difference between this conditional and the climatological feature frequency (which is denoted as the conditional cyclone frequency anomaly $\tilde{f}_{\mathrm{c}}$ or the conditional blocking frequency anomaly $\tilde{f}_{\mathrm{b}}$ ) is a measure of the relevance of the circulation feature for the occurrence of the weather extreme, and the spatial pattern of the conditional frequency gives an indication of their spatial relationship. For precipitation and wind gust extremes, the annual mean frequency (see Fig. 1) is used as a climatological reference, while for hot (cold) temperature extremes the summer (winter) frequency (Fig. 2) is applied. For more details and an example, the reader is referred to Sect. 3.1. Finally, in order to obtain a regionally integrated perspective, the conditional feature frequency anomalies are averaged over six predefined regions as specified in Fig. 3. In addition to evaluating mean frequencies on a geographical grid, $\tilde{f}_{\mathrm{c}}$ and $\tilde{f}_{\mathrm{b}}$ are also transferred to a relative coordinate system, with the location of the extreme event in the centre, and mean values on this relative grid are computed for each region.

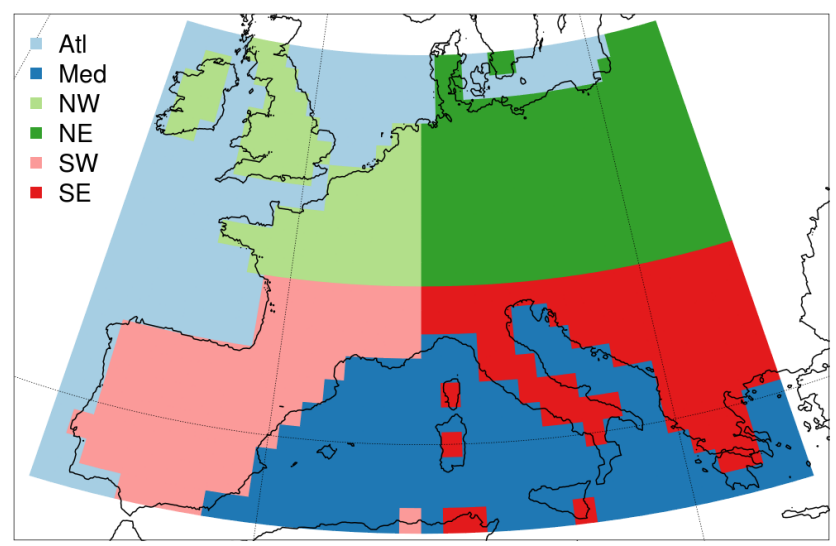

Figure 3. Subregions for regional-scale composite analysis. The sea surface in the target region is subdivided into the North Atlantic and Baltic Sea (Atl) as well as the Mediterranean Sea (Med). The land surface is subdivided into northwestern (NW), northeastern (NE), southwestern (SW) and southeastern (SE) subregions.

\section{Results and discussion}

\subsection{Precipitation extremes}

As a first example, the relevance of cyclones for precipitation extremes at $14^{\circ} \mathrm{E}, 48^{\circ} \mathrm{N}$ (near Linz in Austria) is discussed. This example is also used to explain the methodological approach in more detail. Figure 4a shows the conditional cyclone frequency during precipitation extremes at the target location, which is marked by a cross. Maxima of this conditional frequency greater than $60 \%$ are found over northern Italy and the northern Adriatic Sea. This means that during more than $60 \%$ of the precipitation extremes at $14^{\circ} \mathrm{E}, 48^{\circ} \mathrm{N}$, a cyclone is present in these regions. Furthermore, the conditional cyclone frequency is larger than $50 \%$ southeast of the target location, and adopts values of $20-40 \%$ in a band reaching over the Czech Republic, Poland and eastern Germany towards Denmark and the North Sea. In Fig. 4b, the difference between the conditional and the climatological, annual mean cyclone frequency is shown, the so-called conditional cyclone frequency anomaly $\tilde{f}_{\mathrm{c}}$. The spatial pattern of $\tilde{f}_{\mathrm{c}}$ is similar to the pattern of the conditional cyclone frequency described above, with maxima of the order of 40$50 \%$ to the south and southeast of the target location. $\mathrm{Cy}$ clone frequency anomalies are still larger than $20 \%$ over parts of eastern Europe and $>10 \%$ around Denmark. These high values of $\tilde{f}_{\mathrm{c}}$ indicate that there is a strong relationship between the occurrence of cyclones in these regions and precipitation extremes at the target location. Note that conditional anomalies larger than $10 \%$ typically are highly significant in a statistical sense, as known from selected Monte Carlo experiments (see Pfahl and Wernli, 2012a). However, this statistical aspect will not be discussed further in this paper, since the mere existence of a relationship between the extreme events and atmospheric circulation features (in this 

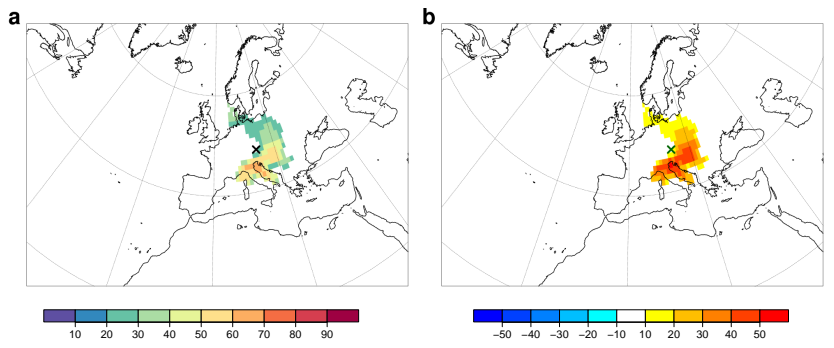

Figure 4. (a) Conditional cyclone frequency and (b) conditional cyclone frequency anomaly $\tilde{f}_{\mathrm{c}}$ for precipitation extremes at the location of the cross $\left(14^{\circ} \mathrm{E}, 48^{\circ} \mathrm{N}\right)$. Fields are only shown where the conditional cyclone frequency differs by more than $10 \%$ from the climatological cyclone frequency of each season.

case precipitation extremes and cyclones), which could be assessed with a statistical test, is clear anyway. In turn, in regions where the conditional cyclone frequency does not differ from the climatological frequency by more than $10 \%$ (i.e. $\left|\tilde{f}_{\mathrm{c}}\right|<10 \%$ ), cyclones cannot be regarded as particularly relevant for precipitation extremes at the target location. Therefore, these regions are masked in white in both panels of Fig. 4 and all following figures. To take into account that precipitation (and also wind extremes) have a specific, spatially varying seasonal distribution (while hot and cold temperature extremes mostly occur during summer and winter, respectively; cf. Sect. 2), grid points are also masked where the conditional cyclone frequency does not differ by more than $10 \%$ from any of the four seasonal cyclone frequencies. This prevents, for example, the detection of heat low anomalies for target grid points where precipitation extremes occur mostly during summer. Only cyclone anomalies clearly different from the climatological cyclone distribution of each season are thus considered. In this way, relatively coherent distributions of $\tilde{f}_{\mathrm{c}}$ are usually obtained, as in the example shown in Fig. 4b.

Cyclones located near the northern shore of the Mediterranean, to the south and southeast of the target location at $14^{\circ} \mathrm{E}, 48^{\circ} \mathrm{N}$, can induce the transport of moist, Mediterranean air masses in a cyclonic path towards central and eastern Europe. In the target region, which is located at the northeastern slope of the Alps, orographic lifting of the associated northeasterly flow as well as the ascent along the cyclone's fronts can lead to heavy precipitation. Several severe floods north of the Alps occurred in such a synoptic setting (e.g. Ulbrich et al., 2003b; Zängl, 2007). Figure 4 provides strong evidence of the climatological relevance of this synoptic situation for extreme precipitation in the target region. The pattern of $\tilde{f}_{\mathrm{c}}$ in Fig. $4 \mathrm{~b}$ can be regarded as a dynamical fingerprint of the extreme events. Note that this pattern closely resembles the classical $\mathrm{Vb}$ cyclone track from the Mediterranean around the Alps towards northeastern Europe (Van Bebber, 1891).

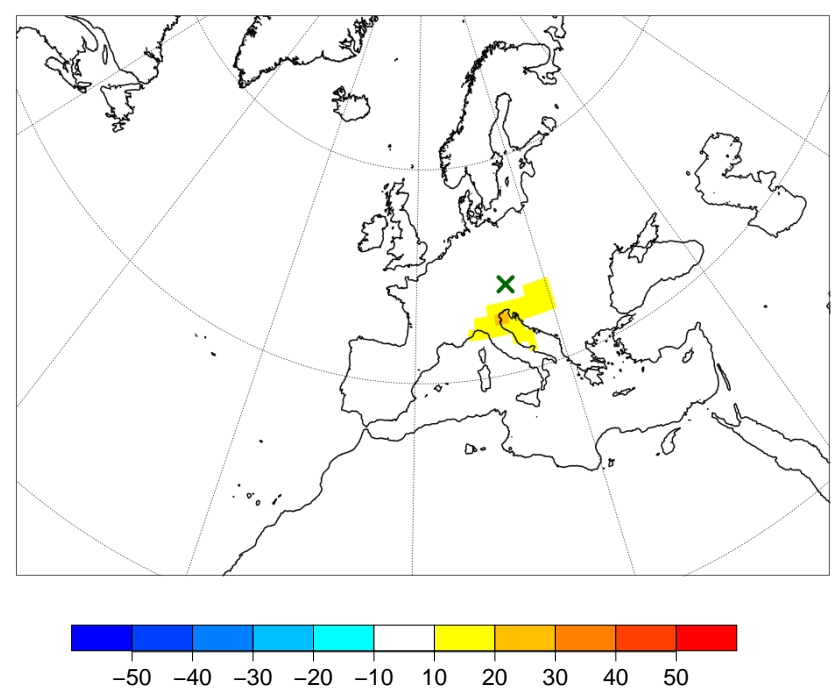

Figure 5. Conditional cyclone frequency anomaly $\tilde{f}_{\mathrm{c}}$ for moderate precipitation events at $14^{\circ} \mathrm{E}, 48^{\circ} \mathrm{N}$. The field is only shown where the conditional cyclone frequency differs by more than $10 \%$ from the climatological cyclone frequency of each season. Moderate precipitation events are defined as events with the six-hourly accumulated precipitation above its 80 th percentile. Note that, since the percentile is defined based on the complete time series including dry days, the 80th percentile corresponds to a relatively small value of $1.2 \mathrm{~mm}(6 \mathrm{~h})^{-1}$.

When not only extreme events, but also moderate precipitation events at the same location are considered, a conditional cyclone frequency anomaly is found in a similar region, but with a much weaker amplitude (Fig. 5). This indicates that cyclones south and southeast of the target location can also be associated with less extreme precipitation, and hence there have to be additional factors besides the presence of a cyclone to foster precipitation extremes at the target location. On the other hand, moderate precipitation events often occur in different synoptic settings, leading to the reduction of the amplitude in Fig. 5 compared to Fig. 4b. Spatially coherent feature frequency anomalies with greatly reduced amplitudes like in this case are generally found for moderate events corresponding to all types of weather extremes discussed in the following (not shown).

When shifting the target grid point from the northeast to $6^{\circ} \mathrm{E}, 47^{\circ} \mathrm{N}$ (near Besançon in France) in the northwest of the Alps, the spatial pattern of $\tilde{f}_{\mathrm{c}}$ changes substantially (Fig. 6a). At this location, not Mediterranean cyclones, but cyclones located to the north, over France, Germany, the UK and the North Sea, are commonly associated with precipitation extremes. Such cyclones lead to westerly flow of Atlantic air masses towards the target location, where orographic lifting and ascent along the cyclone's cold front can cause precipitation. Compared to Fig. $4 \mathrm{~b}$, the distribution of $\tilde{f}_{\mathrm{c}}$ in Fig. $6 \mathrm{a}$ is slightly more spread out, and the maxima (anomalies $>30 \%$ over the North Sea) are less pronounced, indicating larger 


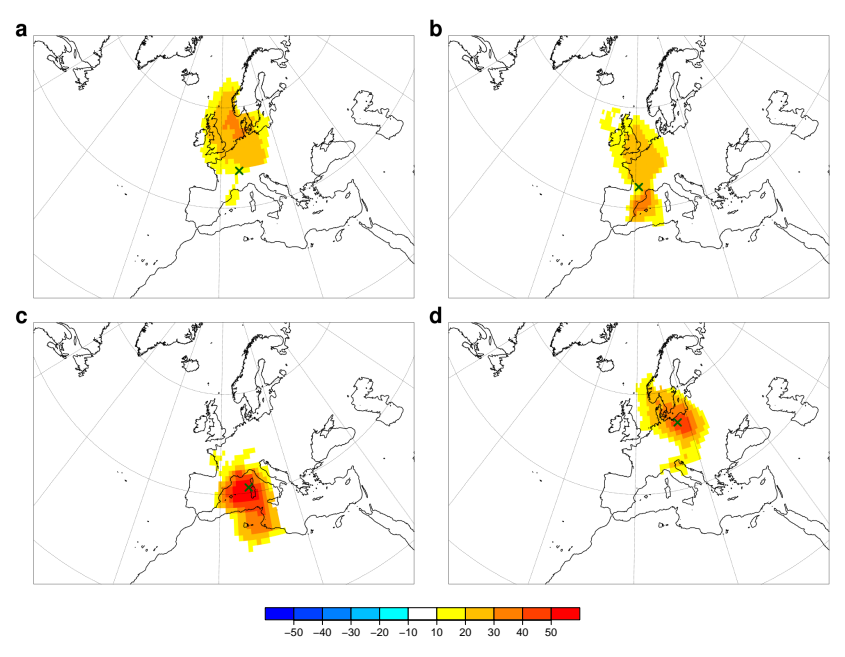

Figure 6. Conditional cyclone frequency anomalies $\tilde{f}_{\mathrm{c}}$ for precipitation extremes at (a) $6^{\circ} \mathrm{E}, 47^{\circ} \mathrm{N}$, (b) $1^{\circ} \mathrm{E}, 44^{\circ} \mathrm{N}$, (c) $8^{\circ} \mathrm{E}, 41^{\circ} \mathrm{N}$, and (d) $16^{\circ} \mathrm{E}, 53^{\circ} \mathrm{N}$. Fields are only shown where the conditional cyclone frequency differs by more than $10 \%$ from the climatological cyclone frequency of each season.

variations in the exact cyclone locations and synoptic conditions associated with extreme precipitation. Precipitation extremes at grid points in the central Alps are influenced by cyclones both in the north and in the south of the Alpine ridge; the patterns of $\tilde{f}_{\mathrm{c}}$ for these points are typically a combination of the patterns shown in Figs. 4b and 6a (not shown). Similarly, precipitation extremes in the Pyrenees are linked to both northerly and southerly cyclones. Figure $6 \mathrm{~b}$ shows an example from the northern slope of the Pyrenees $\left(1^{\circ} \mathrm{E}\right.$, $44^{\circ} \mathrm{N}$, near Toulouse, France), where the westerly flow associated with cyclones over France and the UK as well as the easterly flow due to cyclones over the western Mediterranean can give rise to precipitation extremes. For target grid points further south, the influence of Mediterranean cyclones is more pronounced.

The target grid points discussed up to here are located near elevated topography. For such locations, the direction of the air flow perpendicular to the topography is crucial for the generation of precipitation extremes, which is reflected in the cyclone positions relative to the target location. Figure $6 \mathrm{c}$ and $\mathrm{d}$ shows examples of $\tilde{f}_{\mathrm{c}}$ over the ocean $\left(8^{\circ} \mathrm{E}, 41^{\circ} \mathrm{N}\right)$ and over flat terrain in Poland $\left(16^{\circ} \mathrm{E}, 53^{\circ} \mathrm{N}\right)$. In Fig. $6 \mathrm{c}$, a strongly positive anomaly covers large parts of the western Mediterranean surrounding the target location. Figure 6d has some similarities to Fig. $4 \mathrm{~b}$, with a band of enhanced $\tilde{f}_{\mathrm{c}}$ values reaching from the Mediterranean over eastern Europe towards the North Sea, but the maximum values of $\tilde{f}_{\mathrm{c}}>40 \%$ are found at and close to the target grid point. These examples show that over flat terrain, the dynamical lifting in the vicinity of the cyclone centre is most important for the generation of extreme precipitation. This is consistent with the findings of Pfahl and Wernli (2012a), who quantified this local effect of cyclones on precipitation extremes on the global scale.

To obtain a regionally integrated perspective of the relationship between cyclones and precipitation extremes, Fig. 7 shows the mean conditional cyclone frequency anomalies for regions SW and SE (see Fig. 3 for the definition of the regions) on a geographical grid as well as in a coordinate system with the location of the precipitation extreme in the centre. Precipitation extremes over the Iberian Peninsula and southern France (region SW) are mainly affected by cyclones over the Bay of Biscay and over the Balearic Sea (Fig. 7a). The mean distribution of $\tilde{f}_{\mathrm{c}}$ for extreme precipitation in Italy and the Balkan Peninsula has a maximum over Italy, the Adriatic Sea and the Tyrrhenian Sea (Fig. 7c). This is consistent with the results of Reale and Lionello (2013), who showed that heavy precipitation in the central and eastern Mediterranean is mostly related to Mediterranean cyclones, whereas western Mediterranean precipitation extremes can also be linked to North Atlantic cyclones. In agreement with the study of Jansa et al. (2001), the small displacement between cyclone centres and extreme precipitation events along the Mediterranean coast typically contributes to the transport of moist maritime air masses towards the target location. The average cyclone frequency anomalies on the geographical grid (Fig. 7a and c) are generally less pronounced than anomalies for individual target grid points (cf. Figs. 4 and 6), which is due to the large spatial variability of the synoptic conditions associated with precipitation extremes. They are also less pronounced than the anomalies in the relative coordinate system (Fig. $7 \mathrm{~b}$ and d), indicating that the relative position of cyclone and target location is more important than the cyclone's geographical location in an absolute frame. Mean values of $\tilde{f}_{\mathrm{c}}$ in the relative coordinate system are very high $(>50 \%)$ slightly south of the target location for region SE (Fig. 7d) and less pronounced, but extending more to the northwest for region SW (Fig. 7b). This shows again that lifting near the cyclone centre is important in both regions, while the influence of cold fronts and westerly moisture transport is larger in SW. In regions NE and NW, mean $\tilde{f}_{\mathrm{c}}$ in the relative coordinate system has maxima of the order of 30-40\% near the target location, and anomalies larger than $10 \%$ extend farthest (about $10^{\circ}$ ) in the northerly and westerly directions (not shown).

Anomalies of the conditional blocking frequency during precipitation extremes are typically weak for most target grid points in Europe (not shown). A systematic effect of blocking on precipitation extremes via directing a flow of moisture towards topographic barriers can hardly be detected. For some target locations, mostly in southern Europe, blocking anomalies are found that favour the passage of cyclones over the target region. For instance, blocking over northern Europe can deflect cyclones entering from the North Atlantic towards a more southerly path. These blocking anomalies are substantially weaker than the anomalies of the cyclone frequency closer to the target location and most probably 

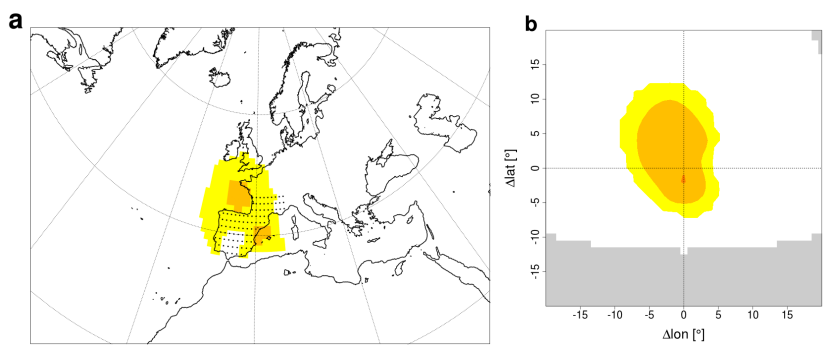

C

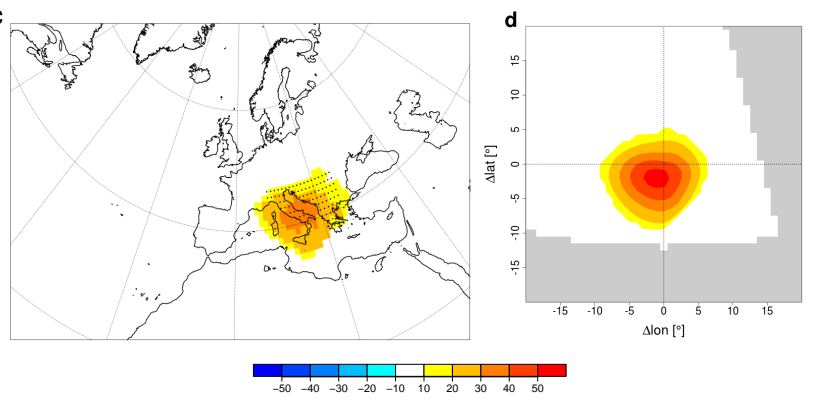

Figure 7. Regional mean conditional cyclone frequency anomalies for precipitation extremes in regions (a, b) SW and (c, d) SE (stippled areas in $\mathbf{a}, \mathbf{c})$. Means in $(\mathbf{a}, \mathbf{c})$ are shown on a geographical grid. $(\mathbf{b}, \mathbf{d})$ show regional means of conditional cyclone frequencies that have been transferred to a relative coordinate system with the location of the extreme event in the centre. Fields are only shown where the conditional cyclone frequency differs by more than $10 \%$ from the climatological cyclone frequency of each season. Grid points outside the analysis region are masked in grey in $(\mathbf{b}, \mathbf{d})$.

influence the occurrence of precipitation extremes only indirectly, via their effect on the cyclones.

In summary, many precipitation extremes in Europe on a scale of $10000 \mathrm{~km}^{2}$ are induced by mid-latitude cyclones. The relationship between cyclones and extreme precipitation depends on the topographic setting. Precipitation extremes over flat terrain and over the ocean often occur in the vicinity of a cyclone centre, where the lifting associated with cyclone dynamics is strong. In regions of more elevated topography, this mechanism is less relevant compared to orographic lifting. In this case, cyclones are displaced from the location of the precipitation and are important for directing the flow of moist air towards the topography. In addition, remote effects of cyclones on precipitation extremes can be associated with ascent along elongated fronts (Catto and Pfahl, 2013) and in warm conveyor belts (Pfahl et al., 2014). Precipitation in mountainous regions often results from the interaction of these different lifting mechanisms (Houze Jr., 2012). Due to these complex interactions, involving also local-scale topography, there is large variability in the spatial relationship between cyclones and extreme precipitation for different target locations.

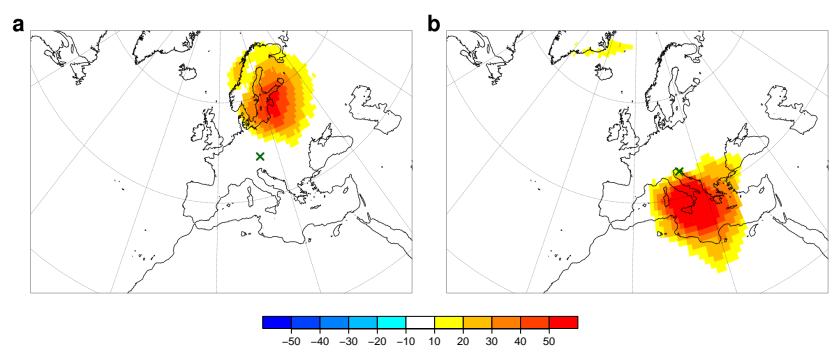

Figure 8. Conditional cyclone frequency anomalies $\tilde{f}_{\mathrm{c}}$ for wind gust extremes at (a) $14^{\circ} \mathrm{E}, 48^{\circ} \mathrm{N}$ and (b) $14^{\circ} \mathrm{E}, 45^{\circ} \mathrm{N}$. Fields are only shown where the conditional cyclone frequency differs by more than $10 \%$ from the climatological cyclone frequency of each season.

\subsection{Wind gust extremes}

The conditional cyclone frequency anomaly related to wind gust extremes at $14^{\circ} \mathrm{E}, 48^{\circ} \mathrm{N}$ (near Linz in Austria, the same location as analysed with respect to precipitation extremes at the beginning of Sect. 3.1) is shown in Fig. 8a. A strong anomaly is found centred over the Baltic states, with maximum values of $\tilde{f}_{\mathrm{c}}$ above $50 \%$. Accordingly, wind storms at this target grid point are often caused by cyclones to the northeast, with a typical distance between target location and cyclone centre of the order of $1200 \mathrm{~km}$. The high wind velocities to the south of the cyclone centre are probably associated with the cyclone's cold front. Note that in some cases smaller secondary cyclones are found closer to the target grid point, often related to a frontal wave (not shown). There is a huge difference between the patterns of $\tilde{f}_{\mathrm{c}}$ linked to wind and precipitation extremes at the target location (cf. Figs. 8a and 4b): while the cyclones inducing precipitation extremes are located relatively close to the target location in the south and southwest, cyclones causing wind extremes are displaced by a larger distance to the northeast. A similar configuration of cyclones and wind gust extremes is found for most target grid points in central Europe. This is also evident from the regionally averaged cyclone frequency anomalies shown in Fig. $9 \mathrm{a}-\mathrm{d}$. The mean pattern of $\tilde{f}_{\mathrm{c}}$ for wind gust extremes in region NE (Fig. 9c) is very similar to the example discussed above (see again Fig. 8a), with a maximum of approximately $40 \%$ over the eastern Baltic Sea, and cyclones typically shifted to the northeast of the target location (Fig. 9d). Cyclones linked to wind extremes over northwestern Europe are often located over the North Sea (Fig. 9a) and are shifted to the north of the target grid point (Fig. 9b). The high mean values of $\tilde{f}_{\mathrm{c}}$ in the relative coordinate system (Fig. 9b and d) indicate that, as for precipitation extremes, the relative position of cyclone and target location is crucial for the occurrence of a wind storm. Nevertheless, cyclones located over the same regions (the North and Baltic seas and surrounding areas) are found to be responsible for wind extremes in many parts of Europe, consistent with previous 

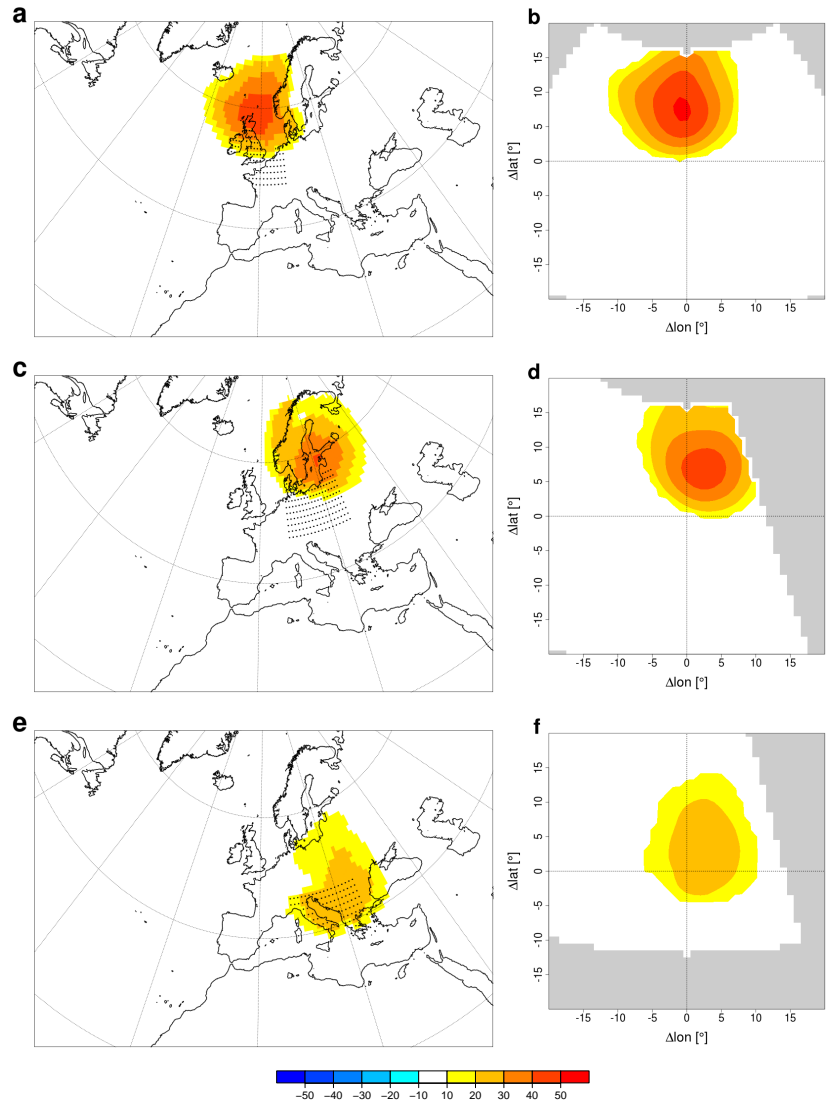

Figure 9. Regional mean conditional cyclone frequency anomalies for wind gust extremes in regions (a, b) NW, (c, d) NE and (e, f) SE (stippled areas in $\mathbf{a}, \mathbf{c}, \mathbf{e})$. Means in $(\mathbf{a}, \mathbf{c}, \mathbf{e})$ are shown on a geographical grid. (b, d, f) show regional means of conditional cyclone frequencies that have been transferred to a relative coordinate system with the location of the extreme event in the centre. Fields are only shown where the conditional cyclone frequency differs by more than $10 \%$ from the climatological cyclone frequency of each season. Grid points outside the analysis region are masked in grey in $(\mathbf{b}, \mathbf{d}, \mathbf{f})$.

studies (Donat et al., 2011; Hanley and Caballero, 2012). This larger coherence of the synoptic-scale forcing for wind gust compared to precipitation extremes (for which the patterns of $\tilde{f}_{\mathrm{c}}$ vary more between different target locations, see again Sect. 3.1) is also linked to a higher spatial coherence of the actual wind extreme events (Pfahl and Wernli, 2012b). This indicates that wind storms simultaneously affect relatively large regions in central Europe.

The linkage between cyclones and wind extremes is considerably different for target grid points in southern Europe, south of the main Alpine ridge. As an example, Fig. 8b shows the pattern of $\tilde{f}_{\mathrm{c}}$ for extreme wind gust events at $14^{\circ} \mathrm{E}, 45^{\circ} \mathrm{N}$ (near Rijeka in Croatia, $3^{\circ}$ south of the target grid point of Fig. 8a). There is a very strong cyclone frequency anomaly over southern Italy and the central Mediterranean Sea, south of the target location. In this case, the wind extreme does not occur near the cyclone's cold front, but in the region of the enhanced pressure gradient north of the cyclone centre. Nissen et al. (2010) also found such a linkage of wind storms in southern Europe to Mediterranean cyclones. The regionally averaged conditional cyclone frequency for region SE has a much larger spread compared to the northerly regions, both in a geographical as well as in an event-centred reference frame (Fig. 9e and f). In addition to Mediterranean cyclones, cyclones over eastern Europe also induce extreme wind gusts, in particular in the eastern part of the region. Locally varying orographic effects and wind systems like the bora can be important here (e.g. Grisogono and Belusic, 2009). The anomalies are much less localised than the cyclone anomalies related to extreme precipitation in the same region (see again Fig. 7c and d). Also for region SW, the spatial spread of mean $\tilde{f}_{\mathrm{c}}$ is relatively large, and maxima are found north of the target region around the English Channel (not shown). All together, this indicates that the synoptic forcing of wind extremes in southern Europe is less coherent than for central Europe.

Figure 10a shows the conditional blocking frequency anomaly $\tilde{f}_{\mathrm{b}}$ for wind gust extremes at $14^{\circ} \mathrm{E}, 48^{\circ} \mathrm{N}$. Positive anomalies are found in a large region extending from the North Atlantic south of Iceland over southwestern Europe to Italy, with maxima of the order of $50 \%$ over the western Mediterranean and the Pyrenees. These blocking anomalies are of the same order of magnitude as the corresponding cyclone anomalies (cf. Fig. 8a). While cyclones are typically located to the northeast of the target location, blocking occurs most frequently in the southwest, i.e. in the opposite direction relative to the extreme location. The role of blocking anomalies for wind extremes can be twofold: Firstly, atmospheric blocking can deflect passing cyclones to regions where they cause high wind gusts at the target location. In the example shown in Figs. 8a and 10a, blocking to the southwest favours the passage of cyclones in the northeast. Secondly and probably more importantly, blocking, which is identified as a persistent anticyclonic vorticity anomaly in the middle to upper troposphere (see Sect. 2), often goes along with a high-pressure anomaly also at the surface. Such high pressure can be instrumental in creating a surface pressure gradient in combination with the low-pressure anomaly associated with a cyclone. The target grid point in Figs. 8a and 10a lies in between the maxima of cyclone and blocking anomalies, in the region of a large pressure gradient and thus of strong geostrophic near-surface winds. Large blocking anomalies to the south and southwest of the target region are also found in the regional mean $\tilde{f}_{\mathrm{b}}$ patterns for regions $\mathrm{NW}$ and $\mathrm{NE}$ (Fig. 11). Again the $\tilde{f}_{\mathrm{b}}$ maxima of locally up to or even more than $40 \%$ are comparable to the $\tilde{f}_{\mathrm{c}}$ maxima shown in Fig. 9a and c. Anomalies of similar amplitude occur in the coordinate system with the location of the wind gust extreme in the centre (not shown). During wind gust extremes at $14^{\circ} \mathrm{E}$, $45^{\circ} \mathrm{N}$, a blocking anomaly is centred over the North Sea, with maxima of $\tilde{f}_{\mathrm{b}}$ above $30 \%$ (Fig. 10b). In this case, the 


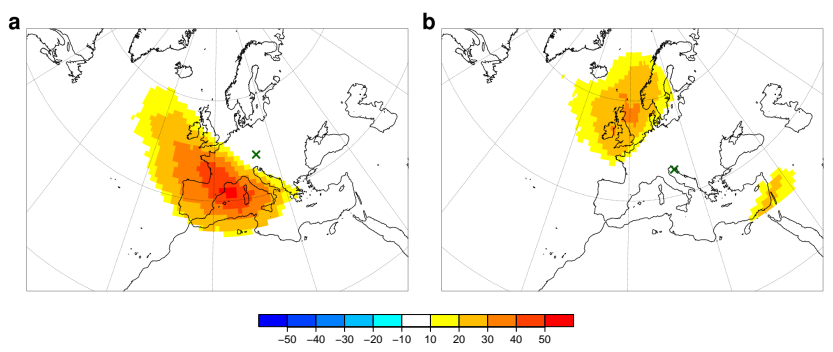

Figure 10. Conditional blocking frequency anomalies $\tilde{f}_{\mathrm{b}}$ for wind gust extremes at (a) $14^{\circ} \mathrm{E}, 48^{\circ} \mathrm{N}$ and (b) $14^{\circ} \mathrm{E}, 45^{\circ} \mathrm{N}$. Fields are only shown where the conditional blocking frequency differs by more than $10 \%$ from the climatological blocking frequency of each season.

blocking is again located in the opposite direction compared to the corresponding cyclone anomaly (cf. Fig. 8b), but its magnitude is substantially smaller. Nevertheless, the same mechanisms of cyclone deflection and the creation of a surface pressure gradient seem to be relevant also for wind gust extremes in southern Europe. Due to the more variable synoptic forcing and the generally smaller blocking anomalies, the regional mean values of $\tilde{f}_{\mathrm{b}}$ are relatively small for region SE (not shown). For wind gust extremes in region SW, mean blocking anomalies $>20 \%$ are located over the Strait of Gibraltar, northern Morocco and northern Algeria.

In summary, wind gust extremes in central Europe are typically associated with cyclones over northern Europe, in particular over the North and Baltic seas. In comparison, the forcing of wind extremes in southern Europe is less coherent, with Mediterranean cyclones being an important factor at many locations. While these findings with respect to cyclones and wind gusts are consistent with previous studies (Donat et al., 2011; Hanley and Caballero, 2012; Nissen et al., 2010), the role of blocking for wind storms has not had much attention yet. Blocking anomalies in the opposite direction of the corresponding cyclone anomalies are often found for wind extremes all over Europe, and this signal is again stronger and more coherent for central than for southern Europe. Such a dipolar anomaly configuration is associated with pronounced surface pressure gradients and thus high near-surface wind velocities.

\subsection{Hot temperature extremes}

Figure 12a shows the conditional blocking frequency anomaly for hot temperature extremes at $1^{\circ} \mathrm{W}, 53^{\circ} \mathrm{N}$ (near Nottingham, UK). Note again that for temperature extremes, which occur predominantly during one season, only those grid points are masked where the conditional frequency does not differ by more than $10 \%$ from the climatological feature frequency of the respective season (cf. Sects. 2 and 3.1). Strongly positive blocking anomalies are found over and around the North Sea, with maxima of $\tilde{f}_{\mathrm{b}}>50 \%$ just northeast of the target location. In addition, weakly negative

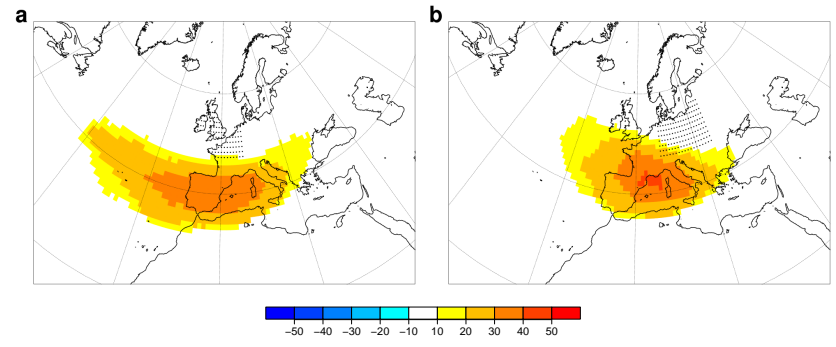

Figure 11. Regional mean conditional blocking frequency anomalies for wind gust extremes in regions (a) NW and (b) NE (stippled areas) on a geographical grid. Fields are only shown where the conditional blocking frequency differs by more than $10 \%$ from the climatological blocking frequency of each season.

blocking anomalies are detected west and east of the main positive anomaly, given an indication of a wave-like disturbance of the mid-tropospheric flow. Blocking at and northeast of the target location can influence the occurrence of hot temperature extremes in several ways: diabatic heating due to the clear-sky radiative forcing and associated surface flux anomalies as well as adiabatic warming owing to the descending motions can increase the temperature in the region of the blocking. In addition, the spatial shift between blocking centre and target location results in a easterly flow of typically warm continental air masses towards the region where the temperature extremes occur. A contribution of easterly transport to hot temperature extremes in the UK is also evident from the Lagrangian analysis of Bieli et al. (2014) (see their Fig. 4a). Note, however, that the horizontal displacement of the air masses is usually rather small, and adiabatic warming clearly dominates their temperature evolution. Positive blocking anomalies in the region of the target location similar to the example of Fig. 12a are found for hot temperature extremes in most parts of central and eastern Europe. This is also reflected in the results of Pfahl and Wernli (2012c), who showed that in these regions a high percentage of hot extremes is associated with co-located blocking. Only in southwestern Europe is there no such relationship between hot temperature extremes and colocated blocking. The example in Fig. 12b (hot temperature extremes at $1^{\circ} \mathrm{W}, 43^{\circ} \mathrm{N}$ ) indicates that for target grid points in Iberia and southwestern France, the blocking anomalies are weaker and displaced further from the target location. This points to a more important role of horizontal temperature advection and, more specifically, the import of continental and Mediterranean air masses from the east or southeast. Instead of the more remote blocking anomaly, there is a small anomaly of the conditional cyclone frequency at and north of the target location for hot extremes at $1^{\circ} \mathrm{W}, 43^{\circ} \mathrm{N}$ (Fig. 13). Most probably, cyclones at this location are of no dynamical relevance for the formation of the extremes though. The anomaly may rather be the signature of heat lows forming as a response to the high near-surface temperatures. For most 


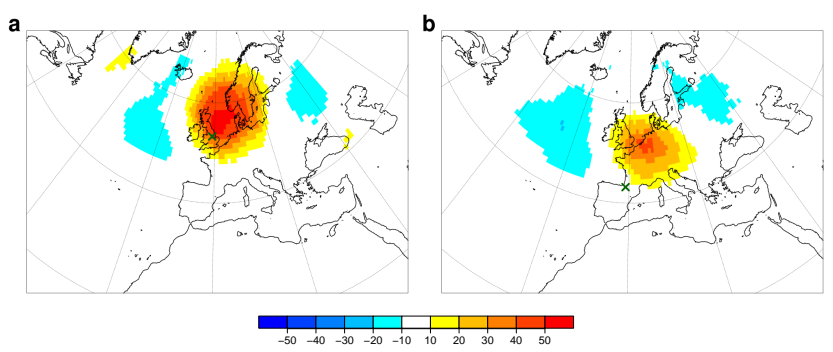

Figure 12. Conditional blocking frequency anomalies $\tilde{f}_{\mathrm{b}}$ for hot temperature extremes at (a) $1^{\circ} \mathrm{W}, 53^{\circ} \mathrm{N}$ and (b) $1^{\circ} \mathrm{W}, 43^{\circ} \mathrm{N}$.

other target grid points in central and eastern Europe, conditional cyclone frequency anomalies are very small, indicating that cyclones do not have a substantial effect on hot temperature extremes in Europe.

The important relationship between hot temperature extremes in central Europe and nearby blocking is also evident from the regional mean patterns of $\tilde{f}_{\mathrm{b}}$ shown for region NE in Fig. 14a and b. The maximum of $\tilde{f}_{\mathrm{b}}$ is shifted slightly to the northeast of the target location, pointing to a contribution from southeasterly advection in addition to the local effects outlined above. Maximum values are higher in the event-centred coordinate system compared to the geographical grid, which indicates that the relative position of the blocking with respect to the target location is crucial. Equally pronounced regional mean anomalies are found for region NW (not shown). For region SE, mean $\tilde{f}_{\mathrm{b}}$ values are smaller and less localised (Fig. 14c and d). The positive blocking anomalies to the northeast of the target region, north of the Black Sea (Fig. 14c), indicate a more important role of horizontal advection. The regional mean pattern of $\tilde{f}_{\mathrm{b}}$ for region $\mathrm{SW}$ is very similar to the example shown in Fig. 12b, with maximum values above $20 \%$ over northwestern France (not shown). Interestingly, regional mean $\tilde{f}_{\mathrm{b}}$ for region Med is never above $10 \%$, showing that blocking has no systematic effect on temperature extremes over the Mediterranean Sea.

In summary, hot temperature extremes in Europe are closely connected to atmospheric blocking. While blocking anomalies occur mostly in the vicinity of the extreme events in central Europe, a larger displacement is found for southern European extremes. This points to a dominant role of clear-sky radiative forcing and adiabatic warming in descending air masses for hot extremes in the northern part of the study region, and a larger importance of horizontal advection of warm continental air masses further south. The results from this section are again consistent with previous studies that found European heat waves to be linked to positive geopotential anomalies in the free troposphere (Cassou et al., 2005; Carril et al., 2008; Stefanon et al., 2012). Note that the direct link between extreme events and circulation features obtained here provides complementary insights into the mechanisms leading to hot temperature extremes as well as a more detailed regional perspective. Furthermore,

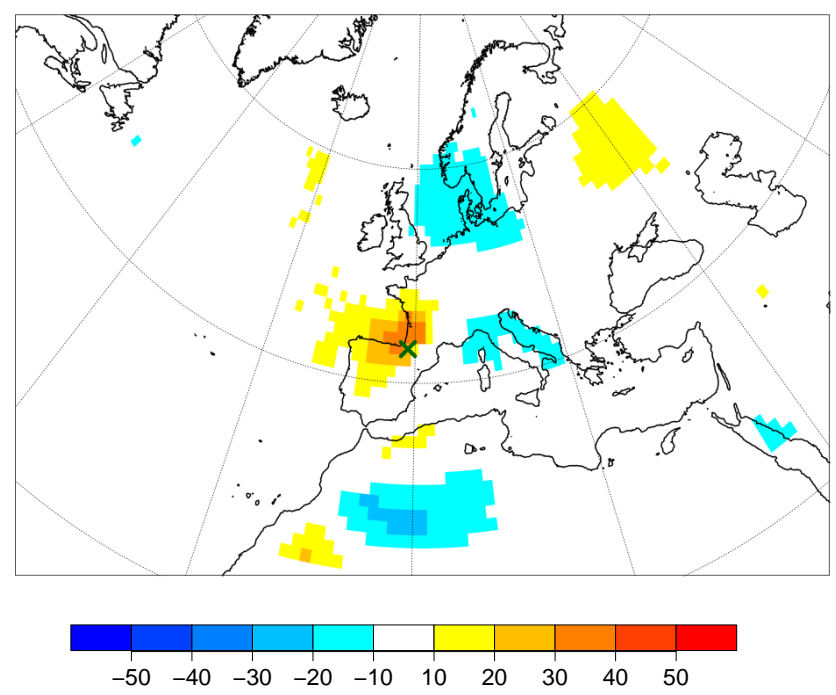

Figure 13. Conditional cyclone frequency anomaly $\tilde{f}_{\mathrm{c}}$ for hot temperature extremes at $1^{\circ} \mathrm{W}, 43^{\circ} \mathrm{N}$.

the present results complement other studies on European heat waves that mainly focused on processes on monthly and seasonal timescales and showed that dry conditions in spring favour the occurrence of hot summers (Fischer et al., 2007; Vautard et al., 2007; Zampieri et al., 2009; Quesada et al., 2012). In particular, rainfall deficits over southern Europe have been shown to precede summer heat waves also in more northerly regions, indicating a northward propagation of the anomaly signal (Vautard et al., 2007; Zampieri et al., 2009). The results presented in this manuscript suggest that this propagation does not happen directly via the transport of warm air masses during the peaks of the heat waves (which correspond to six-hourly hot extremes as defined here), as there is no substantial southerly advection in the prevailing blocking conditions, but rather before the maximum temperatures are reached.

\subsection{Cold temperature extremes}

Conditional blocking and cyclone frequency anomalies for cold temperature extremes at three locations in Europe are shown in Fig. 15. Cold extremes at $9^{\circ} \mathrm{W}, 54^{\circ} \mathrm{N}$ (northwestern Ireland) are associated with a positive blocking frequency anomaly over the North Atlantic, with $\tilde{f}_{\mathrm{b}}$ maxima $>30 \%$ between Greenland and Iceland, at a distance of about $1700 \mathrm{~km}$ from the target location, and slightly negative values of $\tilde{f}_{\mathrm{b}}$ in a large area reaching from the eastern North Atlantic off the coasts of Portugal and Ireland to eastern Europe (Fig. 15a). Cyclone frequency anomalies of opposite sign, with $\tilde{f}_{\mathrm{c}}$ minima $<-30 \%$ south of Iceland and maxima around the Bay of Biscay, are found in similar regions (Fig. 15b). Both the presence of blocking over the northern North Atlantic and cyclones south of the target region are associated with the transport of cold air masses from the northeast and east towards 

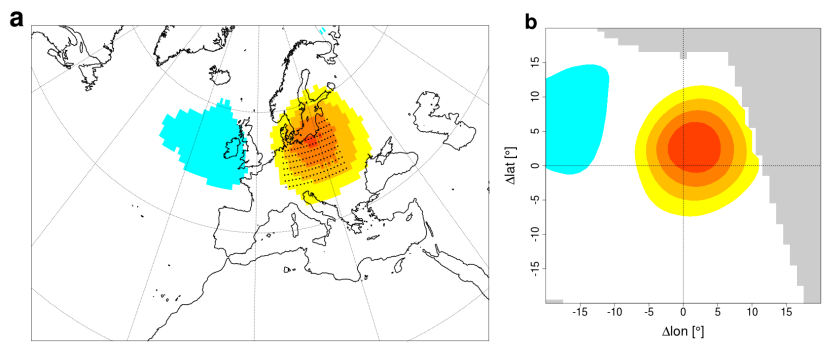

C
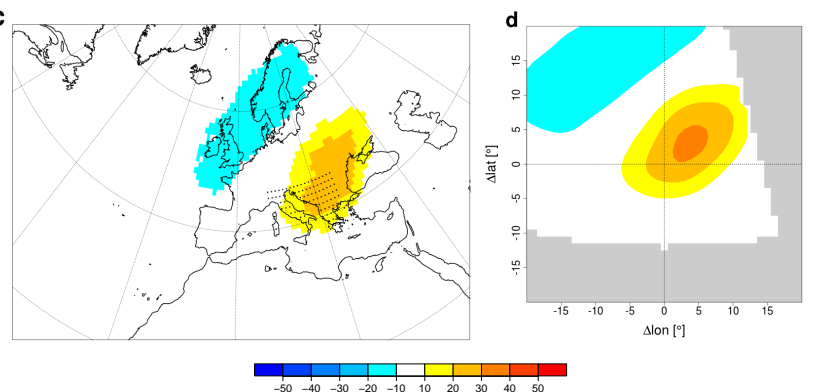

Figure 14. Regional mean conditional blocking frequency anomalies for hot temperature extremes in regions $(\mathbf{a}, \mathbf{b}) \mathrm{NE}$ and $(\mathbf{c}, \mathbf{d}) \mathrm{SE}$ (stippled areas in $\mathbf{a}, \mathbf{c})$. Means in (a, c) are shown on a geographical grid. (b, d) show regional means of conditional cyclone frequencies that have been transferred to a relative coordinate system with the location of the extreme event in the centre. Grid points outside the analysis region are masked in grey in $(\mathbf{b}, \mathbf{d})$.

Ireland. The important role of cold air advection for cold extremes in Ireland is also evident from the trajectory calculations of Bieli et al. (2014). Nevertheless, the anomalies in Fig. 15a and $\mathrm{b}$ are not independent of each other: blocking over the northern North Atlantic favours a more southerly passage of cyclones and thus a reduced cyclone frequency in the region of the block and enhanced values of $\tilde{f}_{\mathrm{c}}$ further south. The symmetry of blocking and cyclone anomalies points to relatively barotropic conditions, in which high- or low-pressure anomalies prevail over the entire troposphere. Note that cold extremes are the only extreme events for which such a symmetry of conditional cyclone and blocking frequencies is found. An equally pronounced blocking frequency anomaly in the North Atlantic as for the target location in Ireland is evident for cold extremes in southern France $\left(6^{\circ} \mathrm{E}, 45^{\circ} \mathrm{N}\right.$, near Grenoble), as shown in Fig. $15 \mathrm{c}$. In this case, the maximum of $\tilde{f}_{\mathrm{b}}$ is located further east, north of Scotland, about $2100 \mathrm{~km}$ away from the target grid point, and positive blocking anomalies still occur over the British Isles, the North Sea, and western Scandinavia. Positive cyclone frequency anomalies are found southeast of the target location (Fig. 15d), with maximum values of $\tilde{f}_{\mathrm{c}}>30 \%$ over the Adriatic and Ionian seas. Again this configuration is favourable for the advection of cold, continental air masses to the location of the extreme events. Finally, for cold extremes at $24^{\circ} \mathrm{E}, 38^{\circ} \mathrm{N}$ (near Athens, Greece), $\tilde{f}_{\mathrm{b}}$ has its maximum over Sweden (Fig. 15e), at a distance of $2600 \mathrm{~km}$

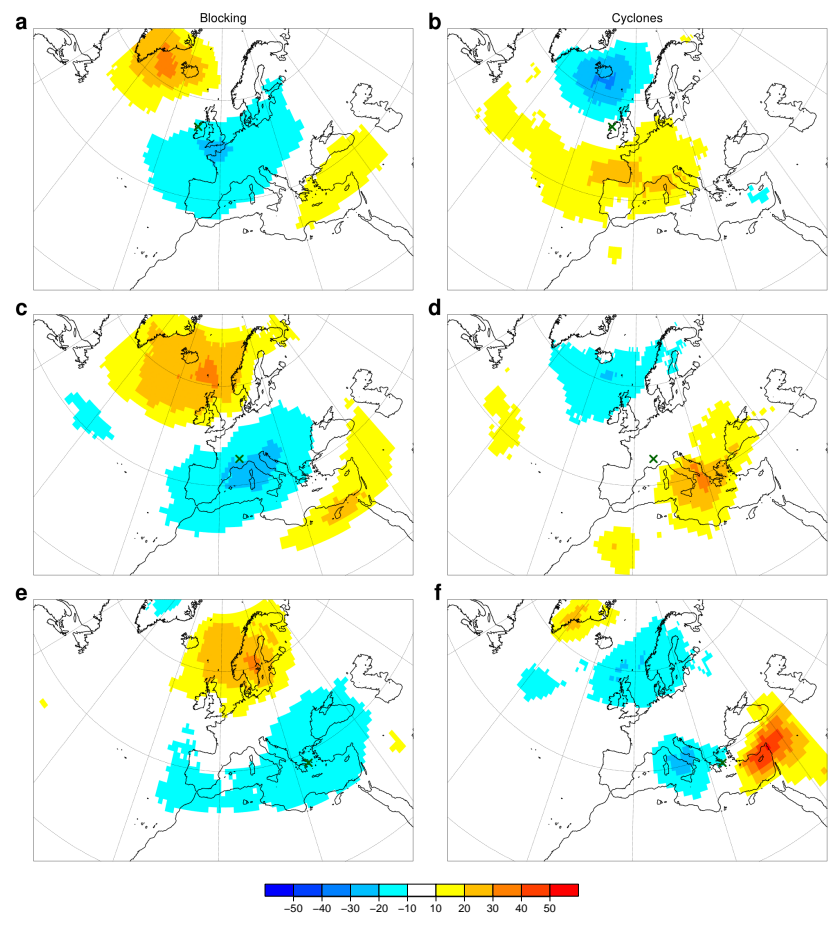

Figure 15. Conditional (a, c, e) blocking frequency anomalies $\tilde{f}_{\mathrm{b}}$ and $(\mathbf{b}, \mathbf{d}, \mathbf{f})$ cyclone frequency anomalies $\tilde{f}_{\mathrm{c}}$ for cold temperature extremes at $(\mathbf{a}, \mathbf{b}) 9^{\circ} \mathrm{W}, 54^{\circ} \mathrm{N},(\mathbf{c}, \mathbf{d}) 6^{\circ} \mathrm{E}, 45^{\circ} \mathrm{N}$ and $(\mathbf{e}, \mathbf{f}) 24^{\circ} \mathrm{E}$, $38^{\circ} \mathrm{N}$.

from the target location, and a pronounced cyclone frequency anomaly $>40 \%$ is found over the eastern Mediterranean and the Middle East. There is still an alignment of positive values of $\tilde{f}_{\mathrm{b}}$ and negative values of $\tilde{f}_{\mathrm{c}}$ over northern Europe, but both slightly negative blocking and cyclone anomalies occur over Italy. A comparison of Fig. 15a-f shows that while the cyclone anomaly southeast of the target location is more pronounced for cold extremes in southeastern Europe, the patterns of $\tilde{f}_{\mathrm{b}}$ are relatively similar, in spite of the large distances between the target grid points. Cold extremes all over Europe are linked to blocking anomalies over the North Atlantic and northern Europe.

This importance of northerly blocking anomalies and cyclone anomalies southeast of the target region is also evident from the regional mean anomaly patterns, as exemplarily shown for region NE in Fig. 16a and b. In contrast to hot extremes, the anomalies in the event-centred coordinate system are not more pronounced than those on the geographical grid (not shown), which corroborates the fact that the relative configuration of anomaly and target location is less crucial for cold extremes. The anomalies are typically stronger for grid points over the ocean (see the regional mean patterns of $\tilde{f}_{\mathrm{c}}$ and $\tilde{f}_{\mathrm{b}}$ for region Med shown in Fig. 16c and d), indicating that large-scale advection is even more important for cold extremes there. This might be related to the influence of additional factors over land, like for instance snow 


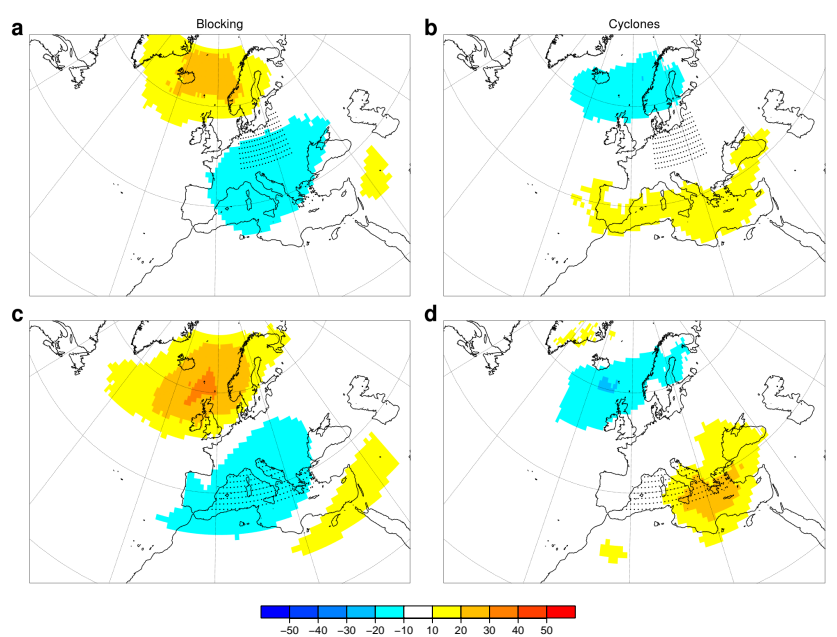

Figure 16. Regional mean conditional (a, c) blocking and (b, d) cyclone frequency anomalies for cold temperature extremes in regions (a, b) NE and (c, d) Med (stippled areas) on a geographical grid.

cover that increases the surface albedo and can thus amplify the cooling. Overall, the blocking and cyclone anomalies associated with cold temperature extremes cover large regions, but are generally less pronounced compared to the other extreme events discussed in the previous sections. This shows that, e.g., the existence of blocking over the North Atlantic is important, but not so much the exact location of the block, which varies between different extreme events. Nevertheless, the same blocking may affect cold extremes at very different locations in Europe. This large-scale character of cold extremes corresponds to the large spatial coherence of the events found by Pfahl and Wernli (2012b). Extremely cold winter conditions often occur simultaneously in many regions on a continental scale (for an example, see Cattiaux et al., 2010).

In summary, cold temperature extremes at most locations in Europe are found to be associated with blocking over northern Europe and the North Atlantic. This is in agreement with previous studies on the influence of blocking on European cold extremes (Sillmann and Croci-Maspoli, 2009; Sillmann et al., 2011; Buehler et al., 2011). The large-scale character of the synoptic conditions related to cold extremes and the similarities between the anomaly patterns for different regions provide an indication why large-scale circulation indices like the NAO are good indicators for the occurrence of such extreme events (see the discussion and references in Sect. 1). Cyclone anomalies associated with cold extremes are found mainly in alignment with the blocking anomalies, and are particularly important for extreme events in southeastern Europe.

\section{Conclusions}

In this study, the conditional frequency of cyclones and blocking during extreme weather events at different locations in Europe has been used to characterise the synoptic-scale circulation conditions associated with precipitation, wind gust and temperature extremes. Despite its simplicity, this approach yields important insights into the physical mechanisms related to weather extremes, since event-based linkages are established to circulation features with well-known physical properties. Furthermore, the method directly reveals the geographical relationship between extremes and circulation anomalies and thus the spatial characteristics of the extreme events and their synoptic forcing. By investigating extreme events at specific grid points, the regional variability of the forcing mechanisms can be assessed. In addition, using a common methodology for different categories of weather extremes allows the evaluation of similarities and differences between these categories.

Some of the results from this study corroborate findings from earlier studies, which were often based on more advanced statistical methods (see Sect. 1 for an overview); others yield novel insight and illustrate complementary aspects of the dynamics of weather extremes. In particular, it has been shown in Sect. 3.1 that the relationship between cyclones and precipitation extremes is very variable and depends on the local topographic setting. Precipitation extremes over the ocean and over flat terrain often occur near a cyclone centre, confirming the importance of lifting mechanisms associated with cyclone dynamics. In contrast, for precipitation extremes near elevated topography, the direction of the flow with respect to the orientation of the mountains is important and determines the relative position of the cyclone anomalies, which are found further afar from the location of the precipitation event. The results presented in Sect. 3.2 reveal that, in addition to cyclones, blocking is also important for the occurrence of wind gust extremes. Blocking and cyclone anomalies are typically found in opposite directions from the location of the extreme event. Such a dipolar setting is especially favourable for the existence of a large surface pressure gradient and thus high geostrophic wind velocities at the target location. Due to the temporal persistence of atmospheric blocking, the predictability of wind storms may benefit from this linkage. Sections 3.3 and 3.4 further illuminate the different role of blocking for hot and cold temperature extremes: blocking anomalies are mostly found in the vicinity of the extreme event for hot extremes, particularly in central Europe, and thus vary in location for hot extremes in different regions. This points to an important role of local adiabatic and diabatic heating. In contrast, cold extremes at very different locations in Europe are associated with similar large-scale synoptic conditions and blocking anomalies over the North Atlantic and northern Europe, often far away from the location of the extreme events. For such cold temperature extremes, horizontal cold air advection is the dominant 
mechanism. Comparing the anomaly patterns related to the different categories of extreme events shows that these categories have very different spatial characteristics, which also correspond to the spatial coherence of the extreme events (cf. Pfahl and Wernli, 2012b). While cold extremes are linked to a common large-scale anomaly signal, the synoptic forcing mechanisms for precipitation extremes are strongly variable and depend significantly on the location of the extreme event. Wind gust and hot temperature extremes show aspects of both large-scale and regionally varying forcing conditions. Furthermore, a comparison of cyclone frequency anomalies between wind and precipitation extremes shows that at certain locations both types of extreme events are caused by cyclones in similar regions. For example, cyclones over the North Sea affect both wind and precipitation extremes in the western Alps. Nevertheless, at other target locations, for instance in the eastern Alps, different cyclones in separate areas are associated with the two types of extreme events (see again Sect. 3.2).

Note that the circulation features identified here are typically much more frequent than the associated weather extremes, indicating that a cyclone or blocking anomaly usually is a necessary but not sufficient requirement for the occurrence of an extreme event. For instance, the depletion of soil moisture can be an additional factor in hot temperature extremes, as shown in previous studies (see again Fischer et al., 2007; Vautard et al., 2007; Seneviratne et al., 2010; Quesada et al., 2012). A comprehensive characterisation of the sufficient requirements for weather extremes in Europe should be established in future research. Furthermore, the present analysis should be extended to capture also the time-lagged relation between circulation features and extreme events. This can yield novel insights, e.g. into the persistence of the anomalies and typical feature trajectories. It can also help to assess potential benefits for medium-range weather forecasts of extreme events. The relationship to cyclones and blocking may be useful in this field, since these synoptic-scale circulation features are typically embedded in larger-scale Rossby waves, which may have upstream precursors far ahead of the event (e.g. Sisson and Gyakum, 2004; Grazzini, 2007; Martius et al., 2008). Finally, the results from the present study can be used for the evaluation of climate simulations with regard to the representation of the atmospheric conditions associated with extreme weather events. They may help in the interpretation of long-term changes of extreme events in future climate projections (for an illustrative example focusing on precipitation changes, see Chang, 2013). As evident from the strong linkages found here, such changes can be caused by variations in cyclone or blocking activity in specific regions.

Acknowledgements. MeteoSwiss and ECMWF are acknowledged for giving access to the ERA-Interim reanalysis data. I am grateful to Heini Wernli (ETH Zurich) for helpful discussions and comments on the manuscript, to Mischa Croci-Maspoli (MeteoSwiss) for giving me access to his blocking identification software, and to three anonymous reviewers for their very constructive comments. The R (R Development Core Team, 2013) open-source software package has been used to produce the analyses and graphics for this study.

Edited by: R. Lasaponara

Reviewed by: three anonymous referees

\section{References}

Andrade, C., Leite, S. M., and Santos, J. A.: Temperature extremes in Europe: overview of their driving atmospheric patterns, Nat. Hazards Earth Syst. Sci., 12, 1671-1691, doi:10.5194/nhess-121671-2012, 2012.

Barriopedro, D., Fischer, E. M., Luterbacher, J., Trigo, R. M., and Garcia-Herrera, R.: The hot summer of 2010: redrawing the temperature record map of Europe, Science, 332, 220-224, doi:10.1126/science.1201224, 2011.

Beniston, M., Stephenson, D. B., Christensen, O. B., Ferro, C. A. T., Frei, C., Goyette, S., Halsnaes, K., Holt, T., Jylhä, K., Koffi, B., Palutikof, J., Schöll, R., Semmler, T., and Woth, K.: Future extreme events in European climate: an exploration of regional climate model projections, Climatic Change, 81, 71-95, doi:10.1007/s10584-006-9226-z, 2007.

Bieli, M., Pfahl, S., and Wernli, H.: A Lagrangian investigation of hot and cold temperature extremes in Europe, Q. J. Roy. Meteorol. Soc., online first, doi:10.1002/qj.2339, 2014.

Buehler, T., Raible, C. C., and Stocker, T. F.: The relationship of winter season North Atlantic blocking frequencies to extreme cold or dry spells in the ERA-40, Tellus A, 63, 212-222, doi:10.1111/j.1600-0870.2010.00492.x, 2011.

Carril, A. F., Gualdi, S., Cherchi, A., and Navarra, A.: Heatwaves in Europe: areas of homogeneous variability and links with the regional to large-scale atmospheric and SSTs anomalies, Clim. Dynam., 30, 77-98, doi:10.1007/s00382-007-0274-5, 2008.

Cassou, C., Terray, L., and Phillips, A. S.: Tropical Atlantic influence on European heat waves, J. Climate, 18, 2805-2811, 2005.

Cattiaux, J., Vautard, R., Cassou, C., Yiou, P., Masson-Delmotte, V., and Codron, F.: Winter 2010 in Europe: a cold extreme in a warming climate, Geophys. Res. Lett., 37, L20704, doi:10.1029/2010GL044613, 2010.

Cattiaux, J., Yiou, P., and Vautard, R.: Dynamics of future seasonal temperature trends and extremes in Europe: a multimodel analysis from CMIP3, Clim. Dynam., 38, 1949-1964, doi:10.1007/s00382-011-1211-1, 2012.

Catto, J. L. and Pfahl, S.: The importance of fronts for extreme precipitation, J. Geophys. Res., 118, 10791-10801, doi:10.1002/jgrd.50852, 2013.

Chang, E. K. M.: CMIP5 projection of significant reduction in extratropical cyclone activity over North America, J. Climate, 26, 9903-9922, doi:10.1175/JCLI-D-13-00209.1, 2013.

Croci-Maspoli, M., Schwierz, C., and Davies, H. C.: A multifaceted climatology of atmospheric blocking and its recent linear trend, J. Climate, 20, 633-649, doi:10.1175/JCLI4029.1, 2007a.

Croci-Maspoli, M., Schwierz, C., and Davies, H. C.: Atmospheric blocking: space-time links to the NAO and PNA, Clim. Dynam., 29, 713-725, doi:10.1007/s00382-007-0259-4, $2007 \mathrm{~b}$. 
Dee, D. P., Uppala, S. M., Simmons, A. J., Berrisford, P., Poli, P., Kobayashi, S., Andrae, U., Balmaseda, M. A., Balsamo, G., Bauer, P., Bechtold, P., Beljaars, A. C. M., van de Berg, L., Bidlot, J., Bormann, N., Delsol, C., Dragani, R., Fuentes, M., Geer, A. J., Haimberger, L., Healy, S. B., Hersbach, H., Holm, E. V., Isaksen, L., Kallberg, P., Koehler, M., Matricardi, M., McNally, A. P., Monge-Sanz, B. M., Morcrette, J.-J., Park, B.-K., Peubey, C., de Rosnay, P., Tavolato, C., Thepaut, J.-N., and Vitart, F.: The ERA-Interim reanalysis: configuration and performance of the data assimilation system, Q. J. Roy. Meteorol. Soc., 137, 553597, doi:10.1002/qj.828, 2011.

Della-Marta, P. M., Luterbacher, J., von Weissenfluh, H., Xoplaki, E., Brunet, M., and Wanner, H.: Summer heat waves over western Europe 1880-2003, their relationship to largescale forcings and predictability, Clim. Dynam., 29, 251-275, doi:10.1007/s00382-007-0233-1, 2007.

Della-Marta, P. M., Mathis, H., Frei, C., Liniger, M. A., Kleinn, J., and Appenzeller, C.: The return period of wind storms over Europe, Int. J. Climatol., 29, 437-459, doi:10.1002/joc.1794, 2009.

Donat, M. G., Leckebusch, G. C., Pinto, J. G., and Ulbrich, U.: Examination of wind storms over Central Europe with respect to circulation weather types and NAO phases, J. Climate, 24, 19501964, doi:10.1175/2010JCLI3224.1, 2011.

Fischer, E. M., Seneviratne, S. I., Lüthi, D., and Schär, C.: Contribution of land-atmosphere coupling to recent European summer heat waves, Geophys. Res. Lett., 34, L06707, doi:10.1029/2006GL029068, 2007.

Grams, C. M., Binder, H., Pfahl, S., Piaget, N., and Wernli, H.: Atmospheric processes triggering the Central European floods in June 2013, Nat. Hazards Earth Syst. Sci. Discuss., 2, 427-458, doi:10.5194/nhessd-2-427-2014, 2014.

Grazzini, F.: Predictability of a large-scale flow conducive to extreme precipitation over the western Alps, Meteorol. Atmos. Phys., 95, 123-138, doi:10.1007/s00703-006-0205-8, 2007.

Grisogono, B. and Belusic, D.: A review of recent advances in understanding the meso- and microscale properties of the severe Bora wind, Tellus A, 61, 1-16, doi:10.1111/j.16000870.2008.00369.x, 2009.

Hanley, J. and Caballero, R.: The role of large-scale atmospheric flow and Rossby wave breaking in the evolution of extreme windstorms over Europe, Geophys. Res. Lett., 39, L21708, doi:10.1029/2012GL053408, 2012.

Houze Jr., R. A.: Orographic effects on precipitating clouds, Rev. Geophys., 50, RG1001, doi:10.1029/2011RG000365, 2012.

Jacobeit, J., Rathmann, J., Philipp, A., and Jones, P. D.: Central European precipitation and temperature extremes in relation to large-scale atmospheric circulation types, Meteorol. Z., 18, 397410, doi:10.1127/0941-2948/2009/0390, 2009.

Jansa, A., Genoves, A., Picornell, M. A., Campins, J., Riosalido, R., and Carretero, O.: Western Mediterranean cyclones and heavy rain, Part 2: Statistical approach, Meteorol. Appl., 8, 43-56, 2001.

Joyce, R. J., Janowiak, J. E., Arkin, P. A., and Xie, P.: CMORPH: A method that produces global precipitation estimates from passive microwave and infrared data at high spatial and temporal resolution, J. Hydrometeorol., 5, 487-503, 2004.

Kenyon, J. and Hegerl, G. C.: Influence of modes of climate variability on global precipitation extremes, J. Climate, 23, 62486262, doi:10.1175/2010JCLI3617.1, 2010.
Leckebusch, G. C. and Ulbrich, U.: On the relationship between cyclones and extreme windstorm events over Europe under climate change, Glob. Planet. Change, 44, 181-193, doi:10.1016/j.gloplacha.2004.06.011, 2004.

Leckebusch, G. C., Weimer, A., Pinto, J. G., Reyers, M., and Speth, P.: Extreme wind storms over Europe in present and future climate: a cluster analysis approach, Meteorol. Z., 17, 6782, doi:10.1127/0941-2948/2008/0266, 2008.

Liberato, M. L. R., Pinto, J. G., Trigo, I. F., and Trigo, T. M.: Klaus - an exceptional winter storm over northern Iberia and southern France, Weather, 66, 330-334, 2011.

Maraun, D., Osborn, T. J., and Rust, H. W.: The influence of synoptic airflow on UK daily precipitation extremes, Part I: Observed spatio-temporal relationships, Clim. Dynam., 36, 261275, doi:10.1007/s00382-009-0710-9, 2011.

Martius, O., Zenklusen, E., Schwierz, C., and Davies, H. C.: Episodes of Alpine heavy precipitation with an overlying elongated stratospheric intrusion: a climatology, Int. J. Climatol., 26, 1149-1164, doi:10.1002/joc.1295, 2006.

Martius, O., Schwierz, C., and Davies, H. C.: Far-upstream precursors of heavy precipitation events on the Alpine south-side, Q. J. Roy. Meteorol. Soc., 134, 417-428, doi:10.1002/qj.229, 2008.

Masato, G., Hoskins, B. J., and Woolings, T.: Winter and summer Northern Hemisphere blocking in CMIP5 models, J. Climate, 26, 7044-7059, doi:10.1175/JCLI-D-12-00466.1, 2013.

Nissen, K. M., Leckebusch, G. C., Pinto, J. G., Renggli, D., U1brich, S., and Ulbrich, U.: Cyclones causing wind storms in the Mediterranean: characteristics, trends and links to largescale patterns, Nat. Hazards Earth Syst. Sci., 10, 1379-1391, doi:10.5194/nhess-10-1379-2010, 2010.

Pfahl, S. and Wernli, H.: Quantifying the relevance of cyclones for precipitation extremes, J. Climate, 25, 6770-6780, doi:10.1175/JCLI-D-11-00705.1, 2012a.

Pfahl, S. and Wernli, H.: Spatial coherency of extreme weather events in Germany and Switzerland, Int. J. Climatol., 32, 18631874, doi:10.1002/joc.2401, 2012b.

Pfahl, S. and Wernli, H.: Quantifying the relevance of atmospheric blocking for co-located temperature extremes in the Northern Hemisphere on (sub-)daily time scales, Geophys. Res. Lett., 39, L12807, doi:10.1029/2012GL052261, 2012c.

Pfahl, S., Sirocko, F., Seelos, K., Dietrich, S., Walter, A., and Wernli, H.: A new windstorm proxy from lake sediments a comparison of geological and meteorological data from western Germany for the period 1965-2001, J. Geophys. Res., 114, D18106, doi:10.1029/2008JD011643, 2009.

Pfahl, S., Madonna, E., Boettcher, M., Joos, H., and Wernli, H.: Warm conveyor belts in the ERA-Interim data set (1979-2010). Part II: Moisture origin and relevance for precipitation, J. Climate, 27, 27-40, doi:10.1175/JCLI-D-13-00223.1, 2014.

Pinto, J. G., Ulbrich, S., Parodi, A., Rudari, R., Boni, G., and U1brich, U.: Identification and ranking of extraordinary rainfall events over Northwest Italy: The role of Atlantic moisture, J. Geophys. Res., 118, 1-13, doi:10.1002/jgrd.50179, 2013.

Quesada, B., Vautard, R., Yiou, P., Hirschi, M., and Seneviratne, S. I.: Asymmetric European summer heat predictability from wet and dry southern winters and springs, Nature Clim. Change, 2, 736-741, doi:10.1038/nclimate1536, 2012.

R Development Core Team: R: A Language and Environment for Statistical Computing, R Foundation for Statistical Computing, 
Vienna, Austria, available at: http://www.R-project.org/ (last access: 1 March 2013), ISBN 3-900051-07-0, 2013.

Reale, M. and Lionello, P.: Synoptic climatology of winter intense precipitation events along the Mediterranean coasts, Nat. Hazards Earth Syst. Sci., 13, 1707-1722, doi:10.5194/nhess-131707-2013, 2013.

Rodriguez-Puebla, C., Encinas, A. H., Garcia-Casado, L. A., and Nieto, S.: Trends in warm days and cold nights over the Iberian Peninsula: relationships to large-scale variables, Clim. Change, 100, 667-684, doi:10.1007/s10584-009-9721-0, 2010.

Santos, J. and Corte-Real, J.: Temperature extremes in Europe and wintertime large-scale atmospheric circulation: HadCM3 future scenarios, Clim. Res., 31, 3-18, 2006.

Scaife, A. A., Folland, C. K., Alexander, L. V., Moberg, A., and Knight, J. R.: European climate extremes and the North Atlantic Oscillation, J. Climate, 21, 72-83, doi:10.1175/2007JCLI1631.1, 2008.

Schär, C., Vidale, P. L., Luthi, D., Frei, C., Haberli, C., Liniger, M. A., and Appenzeller, C.: The role of increasing temperature variability in European summer heatwaves, Nature, 427, 332-336, doi:10.1038/nature02300, 2004.

Schwierz, C., Croci-Maspoli, M., and Davies, H. C.: Prespicacious indicators of atmospheric blocking, Geophys. Res. Lett., 31, L06125, doi:10.1029/2003GL019341, 2004.

Seneviratne, S. I., Corti, T., Davin, E. L., Hirschi, M., Jaeger, E. B., Lehner, I., Orlowsky, B., and Teuling, A. J.: Investigating soil moisture-climate interactions in a changing climate: a review, Earth-Sci. Rev., 99, 125-161, doi:10.1016/j.earscirev.2010.02.004, 2010.

Sillmann, J. and Croci-Maspoli, M.: Present and future atmospheric blocking and its impact on European mean and extreme climate, Geophys. Res. Lett., 36, L10702, doi:10.1029/2009GL038259, 2009.

Sillmann, J., Croci-Maspoli, M., Kallache, M., and Katz, R. W.: Extreme cold winter temperatures in Europe under the influence of North Atlantic atmospheric blocking, J. Climate, 24, 58995913, doi:10.1175/2011JCLI4075.1, 2011.

Sisson, P. A. and Gyakum, J. R.: Synoptic-scale precursors to significant cold-season precipitation events in Burlington, Vermont, Weather Forecast., 19, 841-854, 2004.

Stefanon, M., D'Andrea, F., and Drobinski, P.: Heatwave classification over Europe and the Mediterranean region, Environ. Res. Lett., 7, 014023, doi:10.1088/1748-9326/7/1/014023, 2012.

Toreti, A., Xoplaki, E., Maraun, D., Kuglitsch, F. G., Wanner, H., and Luterbacher, J.: Characterisation of extreme winter precipitation in Mediterranean coastal sites and associated anomalous atmospheric circulation patterns, Nat. Hazards Earth Syst. Sci., 10, 1037-1050, doi:10.5194/nhess-10-1037-2010, 2010.
Ulbrich, U., Brücher, T., Fink, A. H., Leckebusch, G. C., Krüger, A., and Pinto, J. G.: The central European floods of August 2002: Part 1 - rainfall periods and flood development, Weather, 58, 371-377, 2003a.

Ulbrich, U., Brücher, T., Fink, A. H., Leckebusch, G. C., Krüger, A., and Pinto, J. G.: The central European floods of August 2002: Part 2 - synoptic causes and considerations with respect to climatic change, Weather, 58, 434-442, 2003b.

Ulbrich, U., Leckebusch, G. C., and Pinto, J. G.: Extra-tropical cyclones in the present and future climate: a review, Theor. Appl. Climatol., 96, 117-131, doi:10.1007/s00704-008-0083-8, 2010.

Van Bebber, W. J.: Die Zugstrassen der barometrischen Minima nach den Bahnenkarten der Deutschen Seewarte für den Zeitraum 1875-1890, Meteorol. Z., 8, 361-366, 1891.

Vautard, R., Yiou, P., D'Andrea, F., de Noblet, N., Viovy, N., Cassou, C., Polcher, J., Ciais, P., Kageyama, M., and Fan, Y.: Summertime European heat and drought waves induced by wintertime Mediterranean rainfall deficit, Geophys. Res. Lett., 34, L07711, doi:10.1029/2006GL028001, 2007.

Wernli, H. and Schwierz, C.: Surface cyclones in the ERA-40 dataset (1958-2001). Part I: Novel identification method and global climatology, J. Atmos. Sci., 63, 2486-2507, 2006.

Wernli, H., Dirren, S., Liniger, M. A., and Zillig, M.: Dynamical aspects of the life cycle of the winter storm "Lothar" (24-26 December 1999), Q. J. Roy. Meteorol. Soc., 128, 405-429, 2002.

Yiou, P. and Nogaj, M.: Extreme climatic events and weather regimes over the North Atlantic: when and where?, Geophys. Res. Lett., 31, L07202, doi:10.1029/2003GL019119, 2004.

Zampieri, M., D'Andrea, F., Vautard, R., Ciais, P., de NobletDucoudré, N., and Yiou, P.: Hot European summers and the role of soil moisture in the propagation of Mediterranean drought, $\mathrm{J}$. Climate, 22, 4747-4758, doi:10.1175/2009JCLI2568.1, 2009.

Zängl, G.: Interaction between dynamics and cloud microphysics in orographics precipitation enhancement: a high-resolution modeling study of two north Alpine heavy precipitation events, Mon. Weather Rev., 135, 2817-2840, 2007.

Zhang, X., Lu, C., and Guan, Z.: Weakened cyclones, intensified anticyclones and recent extreme cold winter weather events in Eurasia, Environ. Res. Lett., 7, 044044, doi:10.1088/17489326/7/4/044044, 2012. 